\title{
Nieblas, fronteras, trayectos y palimpsestos. Bitácora sobre un proceso de investigación artística desde el Oasis de Niebla de Alto Patache
}

\section{Francisco Navarrete}

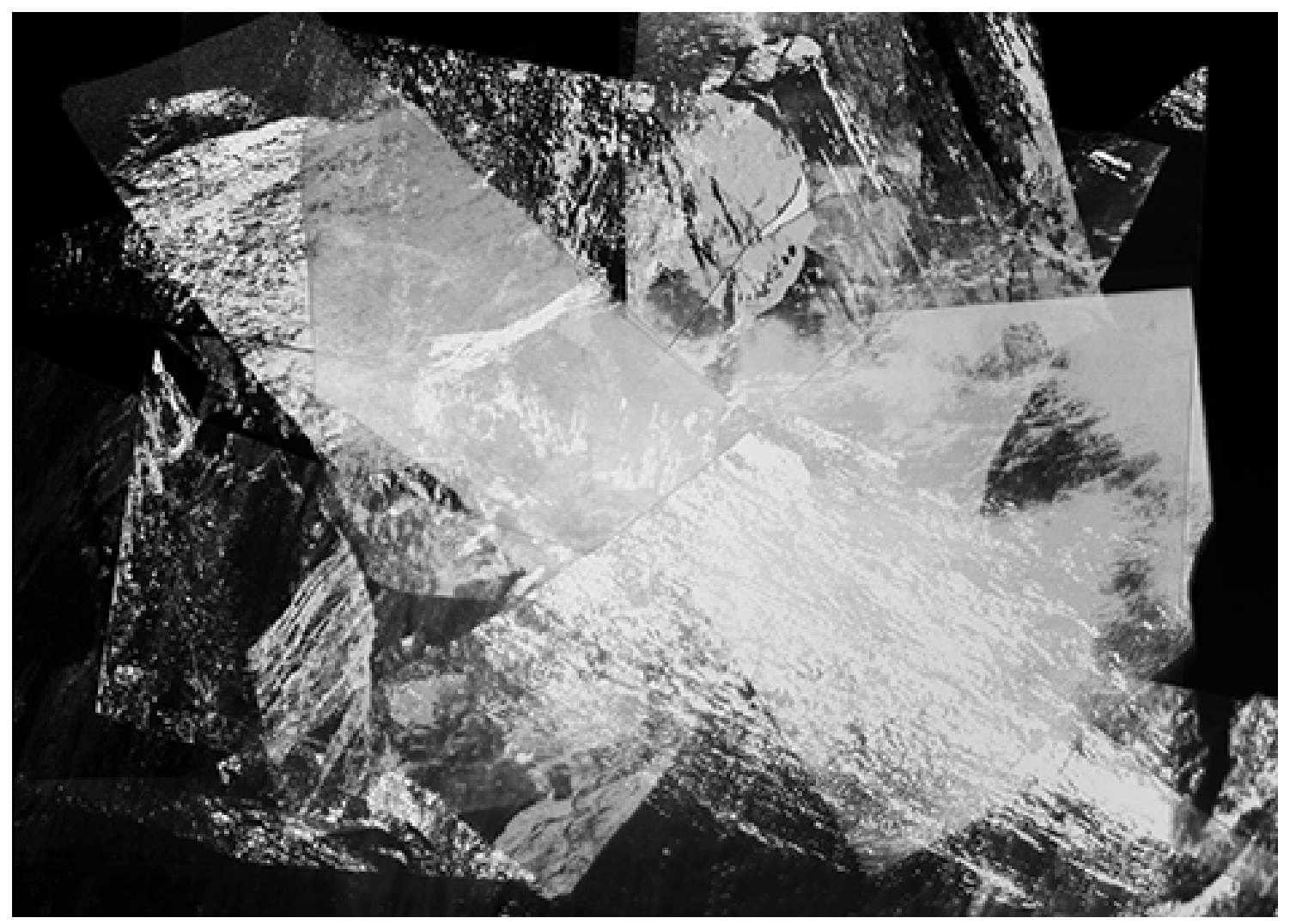

Recibido: 10.05 .2021

Revisado: 14.06 .2021

Publicado: 30.06.2021

Como citar este artículo

Navarrete Sitja,F., 2021. Nieblas, fronteras, trayectos y palimpsestos. Bitácora sobre un proceso de investigación artística desde el Oasis de Niebla de Alto Patache. Inmaterial. Diseño, Arte y Sociedad, 6 (11), pp. 158-183

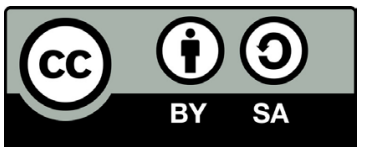




\section{Resumen}

El presente artículo consiste en una bitácora y divagación reflexiva a partir de la revisión y puesta en diálogo de dos procesos de investigación artística desarrollados entre los años 2014-2016 y 2019-2020 en torno al Oasis de Niebla de Alto Patache, Desierto de Atacama, Región de Tarapacá (Chile). Articulando nodos especulativos entre procesos diferidos espacial y temporalmente, el artículo busca establecer conexiones y derivas entre un primer proceso de investigación mediante metodología de trabajo de exploración de campo, y un segundo proceso de investigación mediante metodología de análisis de crónicas y archivos históricos. De esta manera, el artículo va hilvanando preguntas y relaciones entre la calidad material, los sentidos simbólicos y la denominación que da nombre al fenómeno de niebla costera llamada “camanchaca”, transitando también por las nociones de desierto, frontera y visibilidad, y reflexionando sobre sus implicaciones en la configuración del imaginario paisajístico en el desierto tarapaqueño.

Palabras claves: desierto, frontera, niebla, materialidad, no-humano.

\section{Abstract}

This article consists of a reflective log and digression from the review and dialogue of two artistic research processes developed between 2014-2016 and 2019-2020 around the Alto Patache Fog Oasis, Atacama Desert, Tarapacá Region (Chile). By articulating speculative nodes between spatially and temporally deferred processes, this article seeks to establish connections and derivations between a first research process through field exploration work methodology and a second research process through chronicles and historical archives analysis methodology. In this way, the article threads questions and relationships between the material quality, the symbolic meanings, and the denomination that gives name to the phenomenon of coastal fog called "camanchaca," also passing through the notions of the desert, the border, and visibility, and reflecting on its implications in the configuration of the landscape imaginary in the Tarapacá desert.

Keywords: desert, border, fog, materiality, non-human. 
En octubre del año 2014 tuve la posibilidad de participar en una instancia de residencia artística internacional que vinculaba arte, ciencia y territorio, comenzando así un proceso de experimentación artística y exploración territorial junto a un grupo de investigadores de las ciencias ambientales y humanidades, en el Desierto de Atacama, en el norte de Chile.

Esta experiencia de residencia en el desierto -Proyecto NORTE- se fue articulando a través de una serie de viajes, intercambios entre saberes y estadías esporádicas en un centro de investigación "CDA Oasis de Niebla de Alto Patache“, una plataforma y estación científica dedicada al estudio transdisciplinar y a la conservación ambiental de ecosistemas desérticos de niebla (Cereceda, et al., 2008b) en la región de Tarapacá.

Los medios, estrategias y operaciones artísticas con los que quise habitar y dejarme atravesar por el oasis de niebla buscaban propiciar diferentes experiencias sensibles que me permitieran percibir y documentar algunas expresiones climáticas características de este ecosistema costero (Cereceda, et al., 2002), para así posteriormente ensayar -desde el vagabundear en la niebla- posibles conexiones inesperadas que pudieran surgir al poner en diálogo las expresiones atmosféricas del oasis (Cereceda, et al., 2008a), las representaciones de imaginarios paisajísticos locales y los sentidos de materialidad que han constituido la dimensión simbólica de este árido territorio.

De esta manera, la residencia se articularía entonces desde una experiencia vital desplegada en un ambiente no solo catalogado como extremo (Weischet, 1975), sino también en un ecosistema en el que las realidades múltiples se solapan (Haraway, 1997; Mol, 2002) y han sido profundamente moduladas por los distintos aparatos estéticos (Déotte, 2013), e intereses del Estado-nación chileno. Trazando lineamientos estético-políticos que van desde estrategias para consolidar el desierto como una frontera (Benedetti, 2013) requerida para la construcción de la narrativa nacional (Nuñez, et al., 2016), hasta estrategias estético-políticas que permitieron la privatización y comercialización de los recursos naturales, y por consiguiente la explotación y vulnerabilización de las ecologías locales a partir de prácticas extractivistas intensivas (Dalakoglou y Harvey, 2012). 
Por un lado, en relación con los investigadores con los cuales cohabité en esta experiencia (botánicos, eco-antropólogos, ingenieros hidráulicos, geólogos, arquitectos, artistas y otros), me interesó compartir con el grupo una inquietud en torno a las repercusiones simbólicas de la idea de desierto (Nuñez, et al., 2016), en cuanto que noción utilizada para describir este territorio como un recurso natural disponible para su explotación (Heidegger, 1994). Asimismo, me interesó compartir la inquietud con respecto al rol y las formas en que ciertas representaciones visuales y literarias han posibilitado y perpetuado la comprensión de este ecosistema como un espacio estático, vacío y muerto (Nuñez, et al., 2016).

De acuerdo con lo anterior busqué, mediante registros visuales, caminatas y cartografías que repetía diariamente, aproximarme a estas preguntas explorando la densidad material de un fenómeno climático particular de este ecosistema, una expresión atmosférica local popularmente conocida en el norte de Chile como "camanchaca" (Pinto, et al., 2001). Este fenómeno consiste en la formación de unos espesos bancos nubosos que se crean cuando el océano Pacífico toca la superficie terrestre, producto de las relaciones entre corrientes marinas, viento, calor y alta evaporación de agua en la costa, y que luego entran y se desplazan por el desierto en forma de nube estratocúmulo (Cereceda, et al., 2008a), invisibilizando el paisaje y abasteciendo de agua a diversas formas de vida (Wittgenstein, 1988) que ahí coexisten.

En relación con este fenómeno climático, me propuse experimentar y registrar, mediante imagen fija y sonido, las transformaciones materiales de la camanchaca al entrar en contacto con las superficies de los suelos del oasis y las diversas infraestructuras técnicas (Déotte, 2013) industriales desplegadas en el lugar, además de las diferentes manifestaciones lumínicas presentes en este árido ambiente.

De esta forma, apelando a mi formación pictórica, presté especial atención a las calidades materiales y posibilidades evocativas propias de las evaporaciones, las transparencias, los tornasolados, las borraduras, los desplazamientos espaciales, las texturas y las gradaciones cromáticas de la niebla camanchaca (Pinto, et al., 2001). No solo me enfoqué en estas densidades materiales en el momento de su conformación sobre el océano Pacífico y la superficie del farellón costero, sino también en las cualidades y transfiguraciones materiales propias de su desplazamiento desde el farellón costero hacia el interior del desierto, en dirección al altiplano. 
A través de la percepción con el cuerpo inmerso en la niebla y el registro de las materialidades propias del fenómeno atmosférico, pensé que me podrían sugerir -a modo de metáfora y cual cuerpo comunicante- no solo reflexiones en torno a la fragilidad y violencia ejercida en este dinámico y complejo ecosistema desértico, sino también formas de representar la incertidumbre que recae en este ambiente, producto del sentido instrumentalista (Grosfoguel, 2016) que le ha sido atribuido social e históricamente al desierto de Atacama (Romero-Toledo, 2019).

En relación con lo anterior, recuerdo que me interesó especialmente experimentar y registrar las diferentes densidades de la niebla camanchaca, como si esta fuera una especie de interfaz primitiva, una entidad ambiental (Latour, 2008; Despret 2004; Haraway 2003; Weinberg 2019) que solo puede comprenderse de forma sensible en cuanto que superficie de convergencia, zona de contacto y cuerpo relacional (Escobar, 2014; Bonelli 2015). Buscaba percibir con/en/desde la porosidad y la vibración de la niebla su capacidad para afectar cuerpos y atravesar fronteras socialmente construidas (Nicoletti, 2013), una capacidad que irrumpe no solo en el devenir de las formas, superficies y temporalidades que se pliegan en este ecosistema, sino que también nos invita a virar los modos de relación, categorías y sentidos de pertenencia que se han ido petrificando en este territorio categorizado como espacio fronterizo.

Durante el período de residencia y posteriores visitas intermitentes al lugar durante los años 2015 y 2016, produje imágenes digitales y paisajes sonoros que dieron forma a un proyecto expositivo llamado "Aparatos para un Territorio Blando" (Navarrete-Sitja, 2015). Al experimentar con la superposición, la borradura, el pliegue, la repetición y la simulación de imágenes panorámicas paisajísticas, además de con la simulación digital del movimiento a través de imágenes fijas y la simulación digital de la densidad material de la niebla a través del ISO, esta pieza instalativa buscaba generar un relato visual y poético en torno a la incertidumbre simbólica que recae en el territorio desértico tarapaqueño. Así abría preguntas en torno a posibles conexiones entre las formas de representación, la configuración de la mirada y los cimientos instrumentalistas que conlleva la noción de desierto en Chile. 
Años más tarde, en 2019 si no me equivoco, decidí retomar el proceso investigativo que había abierto el año 2014 a partir de la residencia en el Oasis de Alto Patache. A ello se le sumó la realización en paralelo de nuevos procesos de investigación artística desarrollados en otras regiones de Chile: procesos, prácticas y formas de habitar específicas (Ingold, 1993; Ingold 1997) en contextos donde mi modo de practicar el lugar (Lippard. 1997) y las preguntas por la configuración de los imaginarios paisajísticos (Navarro Floria, 2007), se iban nuevamente desplegando (Amade M'charek, 2014) a partir de conexiones imaginativas entre entidades geográficas, formas de representación, la memoria colectiva y la transformación del territorio a través de prácticas extractivistas.

En este sentido, la reiteración de este ejercicio de revisión y reinterpretación de estos procesos territoriales descentrando (Chakrabarty, 2000) la narrativa histórica hegemónica a partir de expresiones materiales geológicas, climáticas o biológicas, se iba convirtiendo en una estrategia cada vez más consciente a la hora de percibir y analizar los distintos procesos, temporalidades y fuerzas que se fosilizan (Steyerl, 2014) en los ecosistemas en que se desenvuelve mi práctica.

Este nuevo estado de comprensión y conciencia de mi quehacer me llevó poco a poco a revisar y dar continuidad, desde una aproximación distinta, al proyecto "Aparatos para un Territorio Blando". Este nuevo enfoque sensible y metodológico, ahora a 12.500 kilómetros de distancia, no sería a través de caminatas, registros fotográficos, grabaciones en video o recopilación de paisajes sonoros, sino que sería a partir del trabajo con documentación, archivo, transcripción de bitácoras de viaje y escritura.

Esta segunda aproximación en torno al fenómeno climático estaría orientada a rastrear cuál o cuáles eran los posibles orígenes y sentidos atribuidos al concepto "camanchaca": los cimientos geográficos, históricos, sociales y culturales que identificaban y denominaban a este particular fenómeno de niebla costera.

En este sentido, más que focalizarme en explorar y representar las propiedades físicas de la niebla y su potencial performativo (Butler, 2002), me interesaba indagar en los sentidos de materialidad previos atribuidos a la niebla en el imaginario paisajístico existente en el Desierto de 
Atacama como posibilidad de rastrear -de rascar-capas ontológicas diversas (Blaser 2016; de la Cadena 2010; Stengers 2005) que conviven en nuestra comprensión de la niebla local. De algún modo, eran formas heterogéneas de practicar y comprender una expresión material a partir de una misma denominación, una misma palabra.

En esta búsqueda de documentación, encontré algunas bitácoras y algunos estudios de campo del eco-antropólogo Horacio Larraín, que cruza investigaciones antropológicas y arqueológicas en la zona (Larraín, 1978; Larraín, 1979), poniendo en valor la relación íntima entre la geografía y las formas culturales que las ocupan y habitan. Asimismo, en la Revista de Geografía Norte Grande -edición número 68-, encontré un documento de los investigadores Manuel Escobar y Magdalena García (Escobar y García, 2017), que recopilaba y relacionaba diversas crónicas y leyendas locales, planteando relaciones entre la geografía y los cambios semánticos generados en contexto de la chilenización de la región de Tarapacá, el proceso mediante el cual la región fue anexada militarmente al territorio chileno, en calidad de estrategia de disciplina del cuerpo social y homogeneización cultural.

La primera crónica citada en la investigación de Escobar y García es un antiguo relato de un comerciante del siglo XVIII, que relataba una leyenda que surgió en el oasis de Pica, a más de 120 kilómetros de distancia del Oasis de Niebla de Alto Patache. Esta crónica hacía referencia a que los habitantes pesqueros y recolectores de la costa del desierto de Atacama, aprovechándose de la invisibilidad que producía la materialidad de la densa niebla costera, "subían con ella hasta las altas tierras del altiplano y asolaban los huertos” (Bahamonde, 1978) de otras comunidades en busca de vegetales comestibles.

De ahí que los camanchacas puedan ser conocidos como "hombres de la camanchaca” (Bahamonde, 1978). La crónica antes mencionada también hacía referencia a que los habitantes de las tierras altas podían predecir el saqueo de los grupos costeros al ver a lo lejos -y a ras de suelo- ascender un espeso, grisáceo e efímero manto de niebla. Como si la densidad material de la niebla (Buci-glucksmann, 2006) y lo que esta imposibilita ver en el paisaje fueran también presentimiento y profecía. 
Una segunda crónica citada en la investigación, un relato escrito por un explorador y pirata del siglo XVI, relataba otra historia muy diferente. Uno de sus fragmentos decía: "en algunas zonas de la costa se han capturado algunos indios pescadores, pobres y casi desnudos que intercambian enseres con los indios de las tierras altas” (Lizárraga, 1999). Llaman a estos indios los camanchaca. Tenían "la piel dura como costra colorada” (Lizárraga, 1999) por beber sangre de lobo marino.

Esta última crónica, con tres siglos más de antigüedad que la primera, sugería que quizás la denominación "camanchaca" habría sido empleada para identificar un grupo étnico, y que luego pasó a identificar la densa neblina costera que se producía en la misma zona que ellos habitaban.

En relación a lo anterior, la investigación de Escobar y García precisaba que en los diccionarios del siglo XIX no aparecía la denominación "camanchaca", y no fue hasta la primera mitad del siglo XX, en pleno proceso de chilenización del Norte (González, 2000) -fase de construcción fronteriza y aculturación de las zonas ocupadas militarmente por el Estado de Chile- que la denominación "camanchaca” aparece en un libro, describiendo los atractivos únicos del paisaje nacional, haciendo alusión a la belleza única del fenómeno de niebla del borde costero.

Más allá de la diferencia respecto a estos dos posibles orígenes de la denominación, ambas crónicas recopiladas a través de archivos por Escobar y García, ello me sugirió en ese momento que la camanchaca -sea la baja y densa niebla costera o los pobladores pescadores itinerantes de la costa desértica- compartían un estrecho vínculo: un modo de plegarse y replegarse espacialmente sobre las tierras de aquel ecosistema que denominamos y comprendemos como desierto. Un desplazamiento físico y temporal donde lo categorizado como humano y no-humano se vuelve sumamente problemático, y que solo puede entenderse de manera relacional, más allá de toda diferenciación contextual entre naturaleza y cultura -entre tantas otras fronteras-: un cuerpo, trayecto y deambular compartido desde la costa del océano Pacífico hasta el interior de la pampa, en dirección al altiplano andino.

Recuerdo que lo más provocador para mí fue pensar cómo ese vínculo simbólico y repliegue espacial por el suelo del territorio aparecía como un intersticio que me invitaba a preguntarme: ¿Quién identifica a 
quién? ¿Por qué la materialidad de la niebla camanchaca tiene respuestas tan ambiguas en este territorio?

En relación con lo anterior, y pensando en la configuración, producción y propagación de los imaginarios paisajísticos de esta zona y en los sentidos y expresiones plásticas de la materialidad en torno a la niebla, me preguntaba: $\_$en este territorio, es aquello categorizado como no-humano quien hace posible el reconocimiento y la identificación con aquello categorizado como humano, o es lo categorizado como humano quien hace posible el reconocimiento y la identificación de lo categorizado como no-humano? ¿Es la camanchaca, en cuanto que niebla, quien hace posible el reconocimiento de las comunidades nómadas del litoral, o son las comunidades denominadas camanchacas quienes hacen posible la identificación de la niebla costera?

Asimismo, volviendo sobre los relatos mencionados por Escobar y García (Escobar y García, 2017), y considerando además los siglos y contexto histórico colonial en el que se inscriben estas crónicas, recuerdo que también me preguntaba: ¿quién reprodujo y propagó tales identificaciones ahora compartidas y asimiladas en los imaginarios paisajísticos de Chile? ¿Bajo qué parámetros, violencias y asimetrías? ¿Con qué intereses se realizó esta identificación mutua entre el fenómeno climático de niebla y los grupos de habitantes nómadas de la costa desértica?

Respecto a lo anterior, enfatizo la expresión "contexto histórico colonial”, ya que los dos relatos ofrecidos por Escobar y García son fragmentos de crónicas realizadas por conquistadores y exploradores europeos en el territorio que ahora llamamos Chile. Viajeros y militares que dejaron su huella y forma de comprender el lugar a través de impresiones y escrituras sobre el reconocimiento del territorio que con los siglos, considerando sus diferencias temporales y horizontes de significado, devinieron -a veces de forma no intencional- parte del imaginario paisajístico y territorial que hoy aseveramos sin cuestionamientos.

Siguiendo con las interpretaciones del material recopilado por Escobar y García, los conquistadores y exploradores posiblemente habían aprendido y deformado la denominación de lo que ahora reconocemos como "camanchaca" en su necesidad de adjudicarla a ciertas manifestaciones materiales del lugar. Expresiones que precisaban identificar, en 
su afán moderno de ordenación del mundo, todo aquello categorizado como otro, diferente, inerte, no-humano, salvaje, incivilizado o bárbaro en algo organizado y controlado, o invisibilizado, silenciado, subsanado o muerto.

En cierta forma, ese gesto de identificación colonial entre las nieblas locales de tipo orográfico y advectivo y los antiguos habitantes nómades del litoral sugiere que fueran denominados como "camanchaca" bajo un correlato geopolítico fundado en el aparato de conocimiento humanista occidental. Me refiero a la división sujeto-objeto, naturaleza-cultura (Descola, 2012) y sentido instrumentalista que este aparato conlleva; es decir, formas de comprender, clasificar y nombrar que fueron posteriormente propagadas por diversos relatos y representaciones que ayudaron a consolidar más tarde la narrativa del Estado-nación chileno en el desierto (Blakemore, 1991).

En este sentido, se podría decir entonces que, en la costa del Desierto de Atacama, lo categorizado como humano y no-humano no puede ser entendido como categorías fijas, sino como agencias confusas e inestables (Viveiros de Castro, 2004). Agencias en tensión constante que han respondido a un constante palimpsesto (Dillon, 2007) de diversos procesos históricos y sociales de ejercer la territorialidad, estrategias de dominio y control sobre las formas de vida que ahí se interrelacionan de manera radical. Como si en la costa del Desierto de Atacama las denominaciones y los sentidos de materialidad apropiada explicaran algo, como si nos devolvieran una representación anhelada; un mensaje pedagogizante incrustado en el paisaje que nos señala lo que debe ser. Conquistadores, exploradores, científicos, patriotas y gobernantes, nos han legado entonces -a través de sus relatos y bajo una misma comprensión occidental y moderna del mundo- que la forma no debe quedar liberada a la naturaleza.

Recuerdo que, en el contexto de una segunda aproximación a este proceso investigativo, y en mi afán de volver a reinterpretar las calidades materiales y rastrear los sentidos simbólicos de aquello identificado como niebla camanchaca, pensaba que ambos -tanto el fenómeno atmosférico como las comunidades costeras- se confundían y solapaban en una misma denominación producto de la indeterminación del origen de dicha palabra. Ese intersticio era un espacio poroso y difuso. Una 
superficie dúctil, un cuerpo incompleto donde las formas de vida se cruzaban, desbordaban y replegaban ante el anhelo de constatar un origen único, una imagen cerrada, sólida y homogénea respecto al territorio.

En esa zona de ambivalencia y multiplicidad, había para mí un terreno fértil para la imaginación y la posibilidad. Un punto de fuga que me invitaba nuevamente a percibir $y$ reflexionar, desde las propiedades $y$ ductilidad de la materialidad de la niebla, cuáles fueron los procesos con que se identificó un determinado ambiente y cuáles son las consecuencias de esa identificación. En este sentido, quizás como ya intenté esbozar antes, la niebla fue y sigue siendo para mí, una forma de descentramiento radical de lo humano, mas no una entidad material que rehúye de la historia y la geopolítica, menos en un territorio saqueado y puesto al servicio de los flujos transnacionales del capital.

En este sentido, se trata de un territorio nombrado a través de deseos hegemónicos a partir de la noción de desierto y frontera por más de tres siglos. Denominaciones sin duda disciplinadoras que no solo contribuyeron a propagar cierta idea de lugar vacío (Nuñez, et al., 2016), sino que propagaron además -en el imaginario colectivo- el ideal civilizatorio de superación de la barbarie en este territorio (Nuñez, et al., 2016), al servicio de la construcción de lo nacional, invisibilizando de la historia la multiplicidad de sus poblaciones, subordinando su prácticas, y propagando además una serie de representaciones sesgadas y uniformantes respecto a lo que "debe ser" comprendido como desierto.

En definitiva, el desierto mismo -más allá de ser un paisaje o una condición atmosférica- aparece entonces como una noción, construcción y representación engañosa y confusa; comprendido muchas veces como espacio vacante, desolado y aislado (Nuñez, et al., 2016). Nociones que no han hecho otra cosa que facilitar la extracción masiva, bruta y muda de diferentes materialidades geológicas de los suelos de la región de Tarapacá.

En relación con lo anterior, me preguntaba: ¿cómo puede percibirse que están imbricadas las materialidades del ambiente que denominamos "desierto", sus representaciones, sentidos simbólicos de materialidad y relaciones geopolíticas? ¿Es por ello, entonces, que lo categorizado como no-humano y humano son en el desierto -al igual que 
en muchos otros territorios modulados por la extracción intensiva de materias primas- no solo agencias cambiantes (Nuñez, et al., 2016), sino también barreras y distinciones permeables cargadas de tensiones por ser mutuamente constitutivos?

De algún modo, las comunidades nómadas conocidas como "camanchacas" devinieron niebla, o la niebla camanchaca devino una comunidad en desplazamiento, invisibilización, instrumentalización, destino fatídico y desaparición. Así, la noción de desierto se enraizó en nuestro imaginario nacional en cuanto que vacío, lugar carente de sentido, recurso disponible para su explotación (Heidegger, 1994), y frontera requerida por el Estado para acceder a esa modernidad tan anhelada.

Al retomar así mi relación con la niebla y el trazado simbólico con los grupos recolectores denominados ambos camanchaca, percibía en esta conjunción un sustrato vital compartido por ambas entidades socio-materiales: la acción no solo del desplazamiento espacial y temporal, sino también la acción del camuflaje, un transitar opaco y titilante, un entrar en contacto con las superficies para garantizar la supervivencia. A través del desplazamiento a ras de suelo, la niebla proporciona subsistencia a diversas formas de vida adaptadas a este ambiente extremo. Y, del mismo modo, camufladas en la niebla, las comunidades nómadas costeras intentaban garantizar su alimentación y pervivencia en el desierto.

Así, retomando nuevamente este proceso de investigación, poco a poco iba entendiendo que, a través de este ejercicio de develamiento y trabajo de exploración de campo, la materialidad de la niebla, los flujos en el territorio y la posibilidad de aparecer y desaparecer, eran vitales. Y que en la "imposibilidad de ver" una vez inmerso el cuerpo en la niebla, ocurría justamente todo lo contrario. La camanchaca, al entrar en contacto con otras superficies, irrumpía en el aparente vaciamiento, en la estabilidad y la transparencia del paisaje, haciendo visible-desde la borradura y el extrañamiento- los sentidos ideológicos adheridos e impregnados en las materialidades del lugar. Las tierras, los conductos, los caminos, los cables, las luces y las torres de alta tensión asociadas a las prácticas de expoliación que desbordan este ecosistema, adquirían ahora -a través de la niebla- otra presencia. 
Desde ese momento, he comprendido la niebla camanchaca no solo como un agente de la historia local, sino también como una expresión material densa e intensa - un sedimento de fuerzas vibrantes-que hace posible el develamiento de la convivencia entre realidades múltiples; una irrupción en nuestra forma de concebir aquello que se ha consagrado en la memoria colectiva de un pueblo: su paisaje y las múltiples capas (Serres y Latour, 1995) de la relación entre la identidad social y ambiental (Clayton, 2003). De alguna forma, a través de este camino de ida y vuelta -de iteración investigativa a lo largo de estos años-, he seguido buscando habitar y dejarme habitar por la niebla -sus capas, nodos, trayectos y posibilidades - como un testigo más - o quizás una forma de resistencia- ante las lógicas y los efectos de la intervención colonial y los procesos de devastación ecosistémica en las tierras de Atacama. 
Aparatos para un territorio blando. Trabajo de exploración de campo. (CFrancisco Navarrete Sitja, 2016.
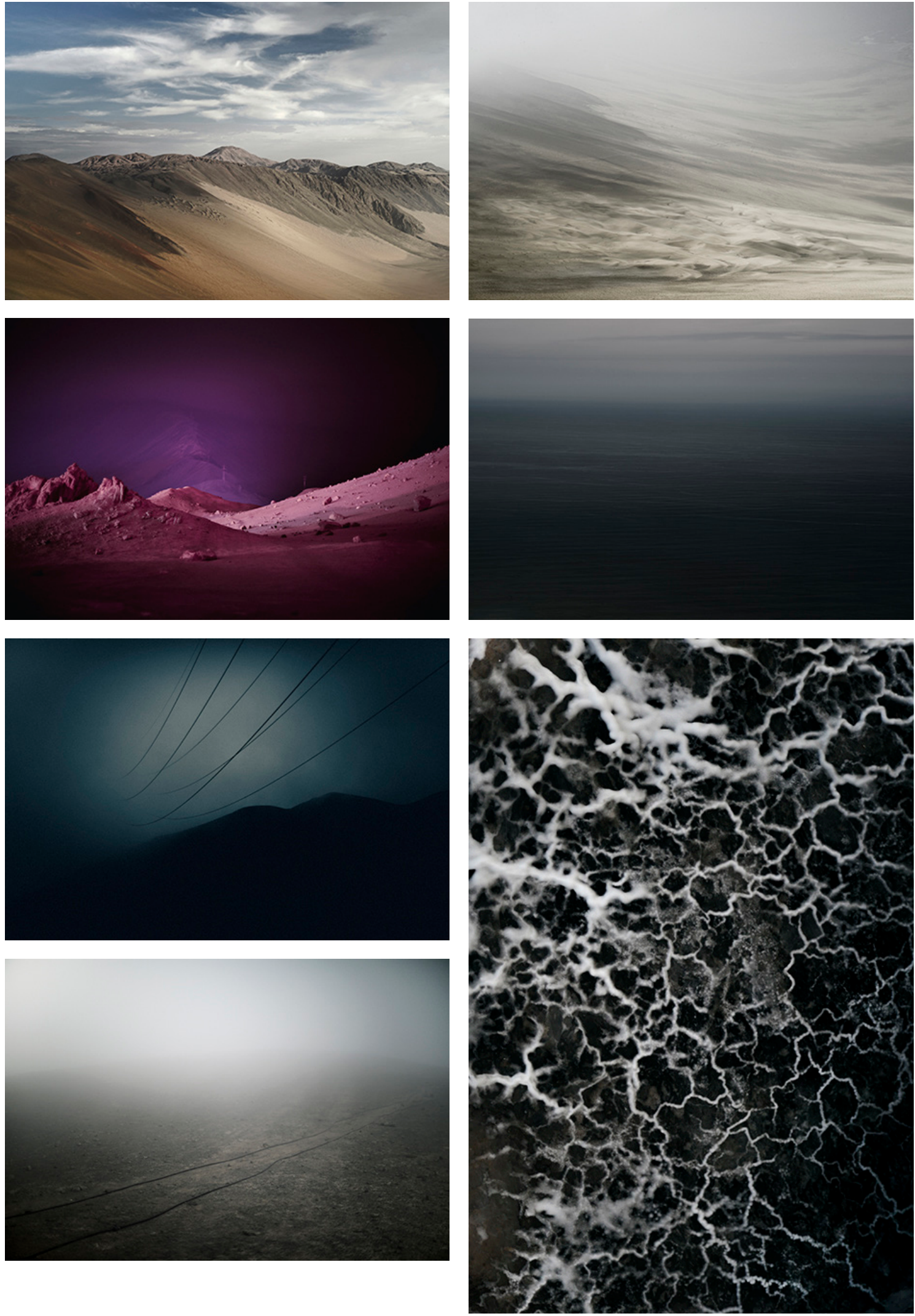
Aparatos para un territorio blando. Trabajo de exploración de campo. CFrancisco Navarrete Sitja, 2016.
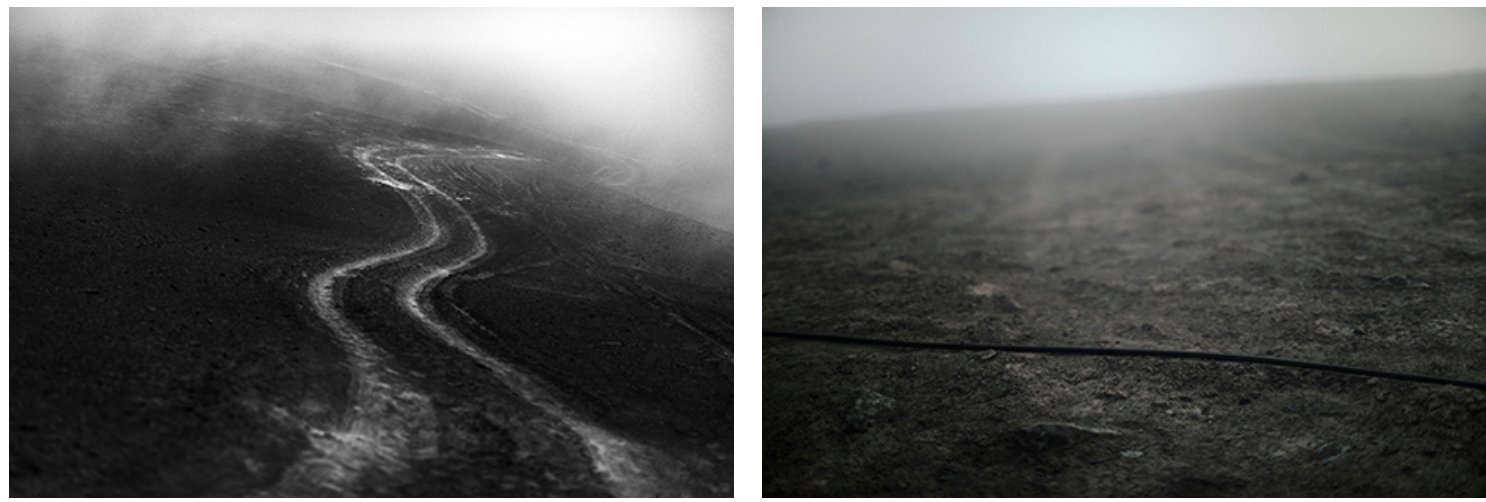

Aparatos para un territorio blando. Captura de pantalla de video animación stop motion. (CFrancisco Navarrete Sitja, 2016
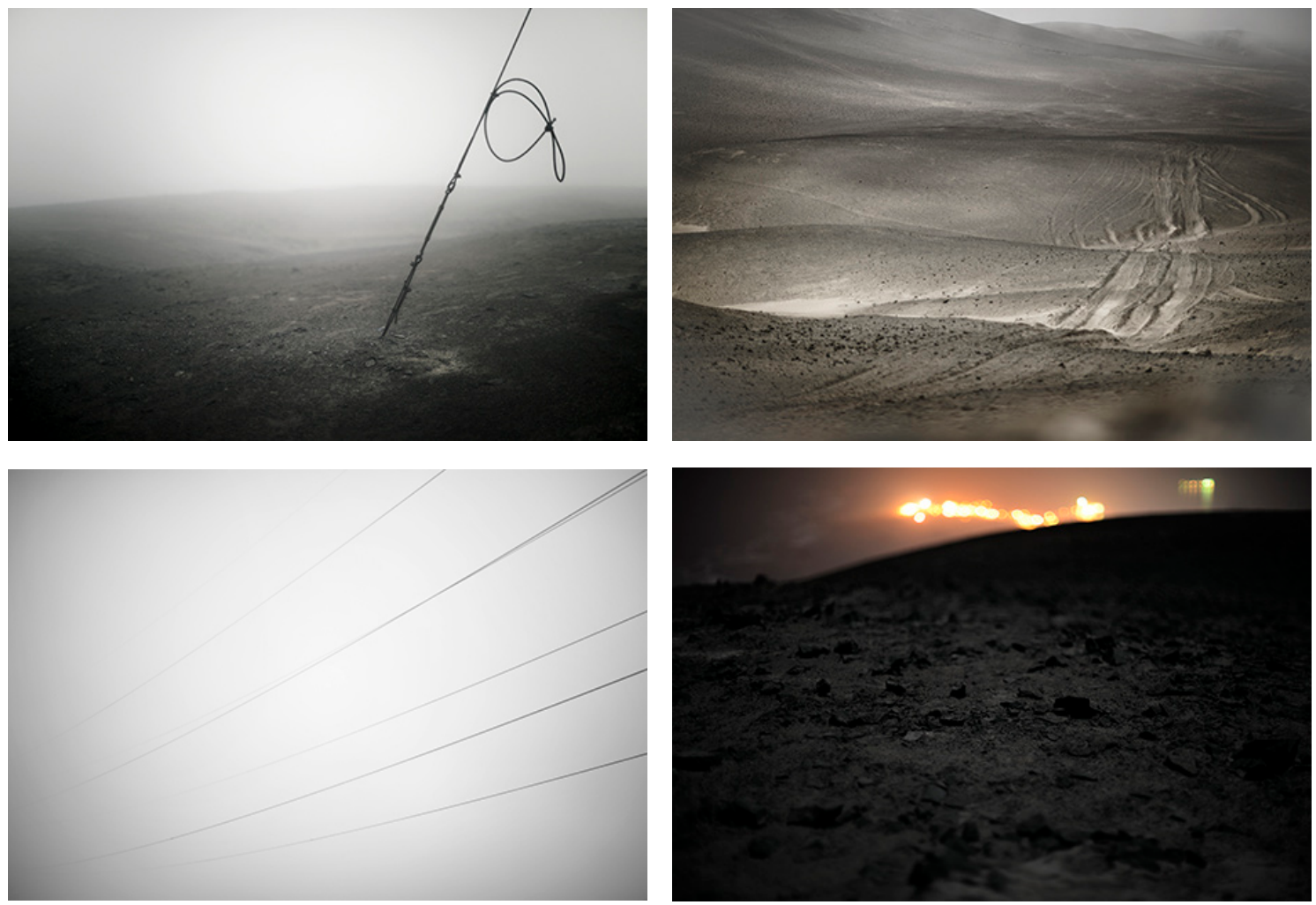
Aladistancia, se podian ver dos franjas paralelas de una porción inorgánica de tierra que absortia totaimente la loz reflejada sobre aquella meseta. Exa una especie de que madura 6 imilar a la que aparece cuando se enciende frego a un papel liso en una de sus orillas. Metáfora ine quívoca de una traza que ha quedado sobre la superficie del si tro que mueve la economia 1 destino de un pais desde el siglo xux. Una imagen hecha - Sensando en términos fotográficos- por el contacto divecto de formas y procedimientos, como cuando la loz arde, penctra e invade, manchan e incendian las mesetas delo sensible, siguiendo a kay.

volviendo ala materia oscura, recuerdo que me llams muchisimo la atención la seca y pétrea calidad monocromática que abundaba en la orilla de la ruta. Esto, en relación con la gama cromática del múltiples. atrostiocosas; escenario que hacia de controponto con sus ocres, y que oscilaban delicata de valores 1 colores pardos, sienas 1 y otros mas cálidos. Las manchas erante entre algunos tonos mas frios umbroso y opaco se manchas eran de un color negro compacto. abyectos $y$ opaco, se exhibian como taturas arenosas. signos

Esas manchas se condecian an la a circulación de diferentes tipos de camiones y maquinaria de trebajominero. En este logar en particular, habia una sugerente proliferacion de ruido que trunaba de vez en cuando por sobre los prolongados silencios de la zona. Las tronaduras, alarmas de retriceso 1 bocinas, eran ecos maquínicos que surcoban grandes distancias. Por suerte, sabia que el desierto e idílico. La aparente serenidad un teritorio inalterado, imperturbable Simulacro de un eventual estado de bienester a parte del e llusorio vacío $(. . .)^{\prime \prime}$.

\section{Fragmento N: 5:}

"(...) la últema parte del recorrido antes de llegar al oasis e ra un pocs más a brupta 1 sesgada. Un estrechs camino de ticrra comenzaba a elevarse por encima delas cáscaras de reca o intersticios que se formaban entre las uniones de los diversqs pampas yquebradas, frme sino que serpenteába mos por la cresta de cada una de las lomas del logar.

Desde ahi, a vnos cuantos kilómetros de distancia, se podia grisdcea que floteba aras a costado una opaca 1densa masa un corredor sobre la ma aras de suelo. Se internaba lentamente por cualquier efecto de perspectiva lineal en lando y aplanando

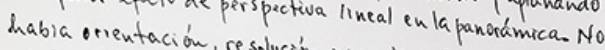
y la luminosidad estaban enuna absoluta de fuga. El parsaje a dind mica de cambio. los contrastes sobre las sombras 1 se ate nuaban levemente a circular en el enterno un viento räpido del logar, comenzó minutos, caila una especie de de rápido ymog frio. A los cada vez mas deusa, oscura de delgoda llovizna que se hacia transformando en oscura y unifarme. El territorio se estaba se disolvia en el caos de una superfice indeterminaciones. movediza. De un momento a otro estébamostable y en la niebla $(\cdots)^{\prime \prime}$.
Fragmentone 3

"(..) Durante el trayecto, todas estas instalaciones sevian a fragmentos, nunca en su totalidad, yinds bren farecian oculterse detrís de un parsaje que por contraste, las distingue como elementos extraños, coma parasitos que irumpen hundiendo susfances enla tierra. En realidad, en la quedida que i ba ingre sando al de siento, solo me era posible divisar las costras negras emplazadas en la orilla del camino, las extensas lineas de torres de a ta templazadas en la orilla del caming inas cuantas hucllas de tierra que sedesviaban 1 adentraban hacia los costados de la carretera asfaltada.

No fue hasta que llegué al oasis y durante la noche -desde la altura Y abropta caida del farellín costeros que logré vel el denso, y teatralmente iluminado, emplazamiento industrial sobre la planicie costera de Punta Patache. Se podia apreciar la prolongada linea de hums que emanaba desde una de suschimeneas. De la mursma forma, se podian disisar unas cuantus luces diminutas en las caletas y a sentamento de pescadore sde Chanavayita, Chanavaya y Caleta Cánamo, entre otros pequenós cirevlos billantes e intermitentes que se desplazaban lantamente por la lejana carretera que recorre la Terraza marine.

Quevemos Ser pais y Somos apenas parsaje, decia Nicanor larra. Recuredo que las loas ye reflectoras de la plante termoeléctrica nada tenian que verconla calidez de la loz natural, más parecianoeléctrica nada tenian inorgánica emplazada frente a la costa. Asimisms, pero de forma - cuales protofotogosible divisar tenuemente eula terraza marina galaxia-, el reflejs se miles destintas enla inmensidad de la acuosa de las pixinas de miles de luas brillantes sobre la superficie acuosa de las pixcinas de decantación y residous tóxicos. Recordando la lectura Didi-Huberman sobre Pasolini, ho podia dejar de asociar ám los reflectores de la industria sobreexponian los cuerpos a esas humibles 1 pequéras casas agrupadas en la caleta contigua a la termoeléctrica e económicos por la la económicos por la la industria en mercancia $(\cdots)$ ".

Fragmento $\mathrm{N}^{3} \mathrm{f}$ :

"(‥) Una de las cosas más curiosas que ocurrian una vez inmerso enese espacio ambiguo, difuso e inmaterial, es que aquellos elementos externos que podrlan dar cuenta de algún signo concreto de temporalidad desaparecian del todo. Ast, esa reconscidad capacidad que posee el desierto para preserviar elementos debido a suculta salinidad jescasez de agua, pasaba -gracios a la urebla- a último plano.

Alinterior de esta, el territorio seconfiguraba como un espacio atemporal capaz de andlar yatravesar el trempo en tanto caltamiento de aquello que material mente hos sugrere un ritmo, duración ointervalo. Es que eu la dispersión total de la loz-efecto propiciado por una variación en la dirección y velecidad de las longitudis de onda del espectro luminoso sobre ona determinada soperficie-parece no habe lugar olegibilidad para un sistema del trempo y sus estratos. No mientras este parezca ausentarse por no tener una imagen de símismo. Era algo contradictorio, pues cuando desaparecia tola traza del trempo y es pacio preducto del fenómeno clemático, la niebla hacia de ella misma, como una vibración del trempo hecha sensible. El parsoje era cubierto por un flojo movil, desmaterializedo, diferrdo 1 discontinuo. El espacio - melancólicu y cósmico- se curvaba, se hacia oblicoo. Era pura plastrcidad y fluidez en el ambiente

Mientras caminaba y realizaba una serie de regrstros por el lugar, no podia dejar de pensar en las miltiples manifestaciones de translucidez del fenómeno. Tamizada por la bruma, la luz era capaz de anular todo proceso de representación; toda la fantasmagoría dela mimesis. Lo mismo ourrirá con los a mbrentes a cústicos subyugados a la extrema circulación del viento. Este ascendia tan violentamente a ras de suelo desde el fare lión costero, que era mu dificil registrar $\sin q u e$ el audio se transformará en un registro sonoro sobreapuesto bor el clima. El forido - ondas de un cuerpo vibratorio que se propagan en un medio elástico por la comprensión yrarefacción de las particulas- daba cuenta de una perturbación y latencia que reverberaba en todas las direcciones dela soperficie cubrerta por la bruma desértica $(\cdots)^{\prime \prime}$. 
Aparatos para un territorio blando. Captura de pantalla de video animación stop motion. (CFrancisco Navarrete Sitja, 2016
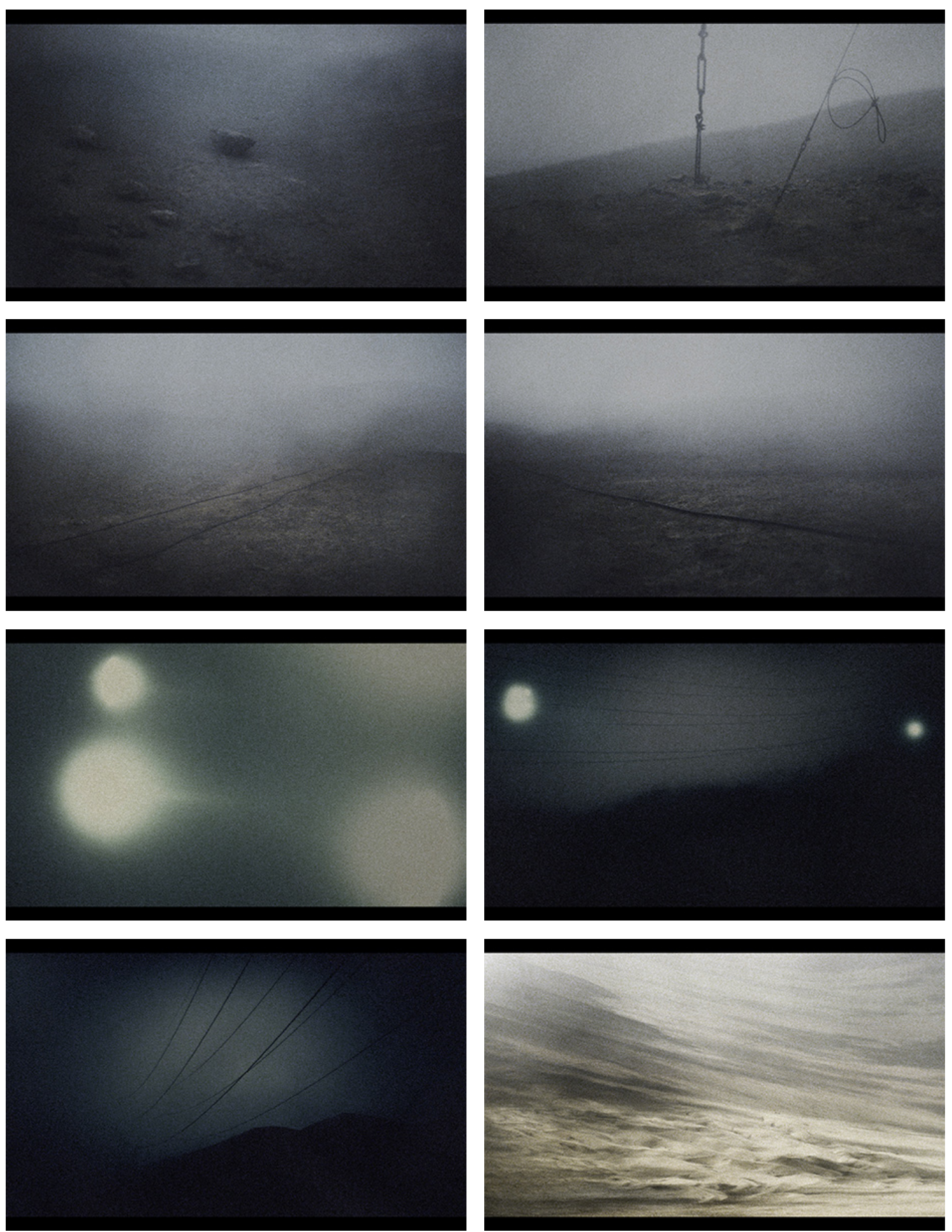

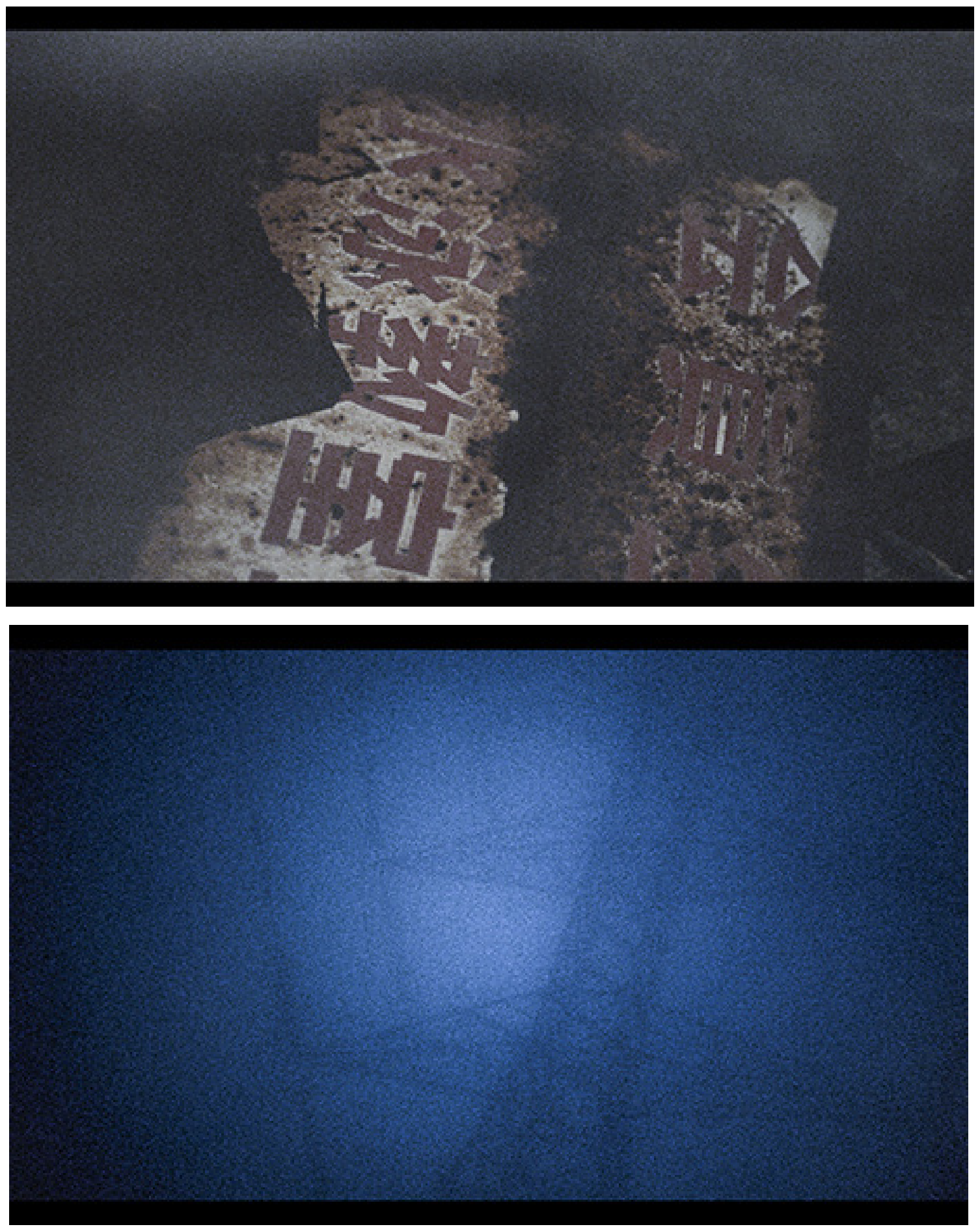
176

PROYECTO

Inmaterial 11_Proyecto_Nieblas, fronteras, trayectos y palimpsestos. Bitácora sobre un proceso de investiga-

cion artística desde el Oasis de Niebla de Alto Patache_Francisco Navarrete

Aparatos para un territorio blando. Notas borrador artículo. (CFrancisco Navarrete Sitja, 2021

Respecto a este fenomeno de niebla, pretendia tener dos aproximaciones muj concretas. La primera, experimentar p registrar-mediante imagen 7 Sonido- las transformaciones materiales de la camanchaca al entrar incontocto conlas superficies de los suelos, infraestructuras técnicas desplegadas on el contexto op dimensiones Lumínicas propias de este árido ambrente. Esto, poniendo atención a las evaporaciones, transparencias, fornasolados, densidades borrosas, desplazamientos espaciales, texturas 1 gradaciones cromáticas de la niebla sobre el farellón costero nortino, frente al océano pacífico. 
Propiedades materiales de la niebla que en ese momento pensé me podrian sugerir - a modo de metáfora y enal cuerpo comunicante- no solo reflexionar la fragilidad yuidencia ejercida en este dinamico ecosistema, sino tambrén representar la incertidumbre simbólica que recae en este ambiente, producto de la expansion del pensamien to teens-cientifico y sentido instrumentalista que le ha sido a tribuido al desrerto chileno.

Respecto a loanterior, enfatizo la expresión "contexto histórico colonial", ya que los dos relatos mencionados son fragmentos, descripciones realizadas por conquistadores 1 exploradores europeos. Quienes dejoron su huella a través de impresiones y escrituras que con el trempo, considerando sus diferencias temporales 1 horizontes de significado, devinieron un imaginario territorial que aseveramos $\sin$ cuestionamientos en la actualidad. Exploradores que posiblemante habrian aprendido y deformado la denominación de lo que a hora reconocemos como "camanchaca" en su necesidad de adjudicarla a ciertas expresiones materiales. Expresiones que precisaban identificer en su a fán moderno de ordenación del mundo, ahi donde todo a quello categorizado como otro, 10 diferente, no-humano, saluaje, incivi lizado o bárbaro debia ser de algín modo organizads, controlado, invisibilizado, subsanado o muerto.
En esta segunda aprokimación, más que focalizarme en explorar y representar las propiedades f'sicas de la niebla 1 so potencial performativo, me interesaba indagar en los sentidos simbolicos atribuidos a la niebla en el imaginarid territorial existente en el desierto. Esto, como posibilidad de rastrear - de rascarcapas ontológicas diversas respecto a la miebla local. De algún modo, formas heterogéneas de practicar $y$ comprender una expresión material a partir de una misma denominación. Para tales efectos, a partir del trabajo de exploración de compo en distentas zonas de la localidad, recopilé e investigué distintas cronicas, de las cuales dos llamaron mi atención.

Ductos, cables, mangueras, Maquinaria, caminos, metales, loces, manchas, plásticus y torres de alta tensión vinculadas a las prácticas Extractivas que desbordan este ambrente, adquirian otra presencia al ser experimentados desde el fenómeno de niebla. Ya no me parecian más invisibles por exceso de familiaridad. Desde ese momento, comencé a comprender la niebla camanchaca no solo como agente de la historia local, sino tambrén coms expresión material que hace posible on develamiento e irrupción de nuestra forma de concebir aquello que se ha consagrado la memoria colectiva. Una idea de desierto construida bajo ciertos parámetros de "haturaleza". De alguna forma, comenzaba a percibir la niebla como testigo silencisso de los efectos duraderos del colonialismo en las áridas tierras y vapores de Atacama. 

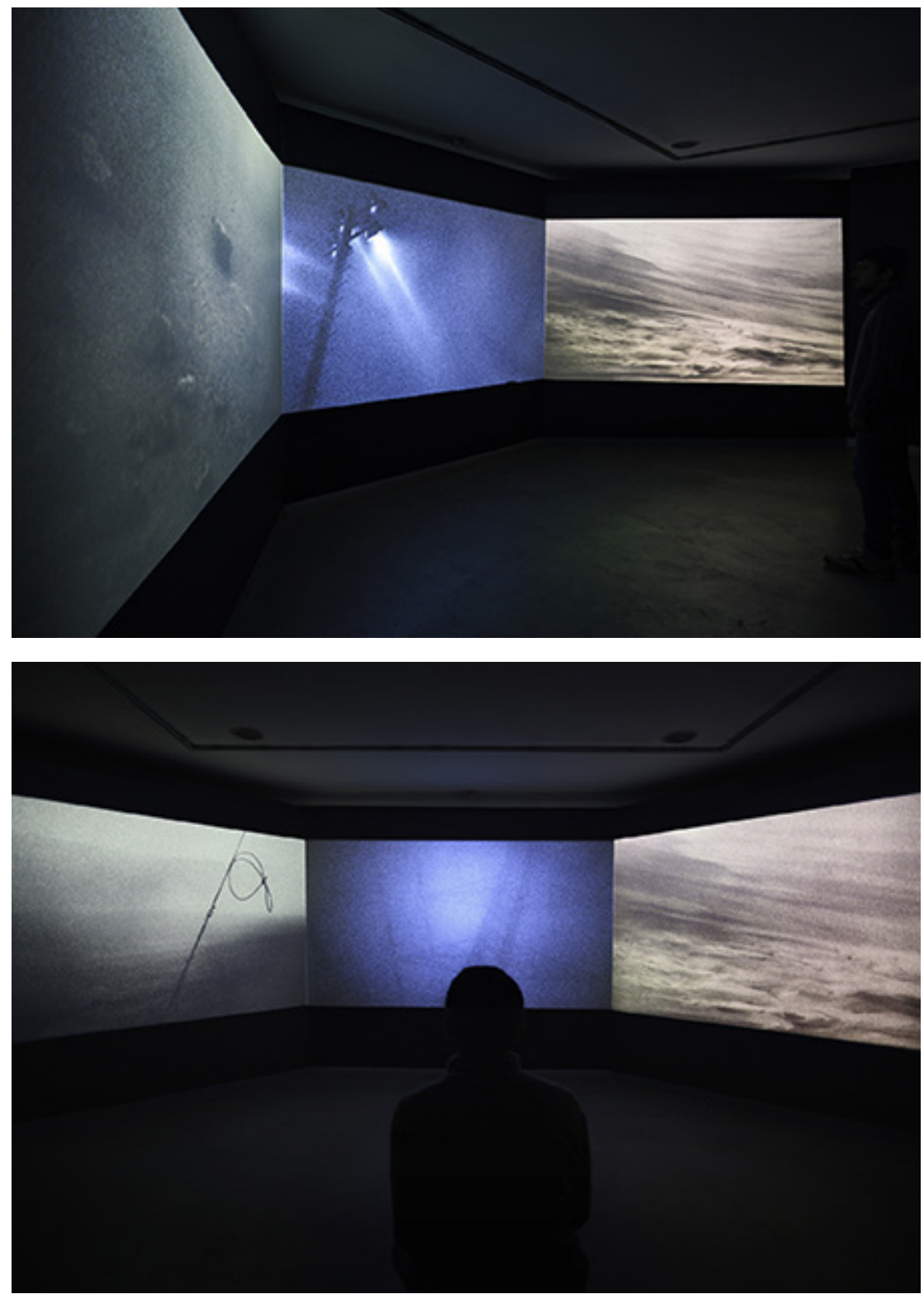
Aparatos para un territorio blando. Collage con material de archivo. CFrancisco Navarrete Sitja, 2021.
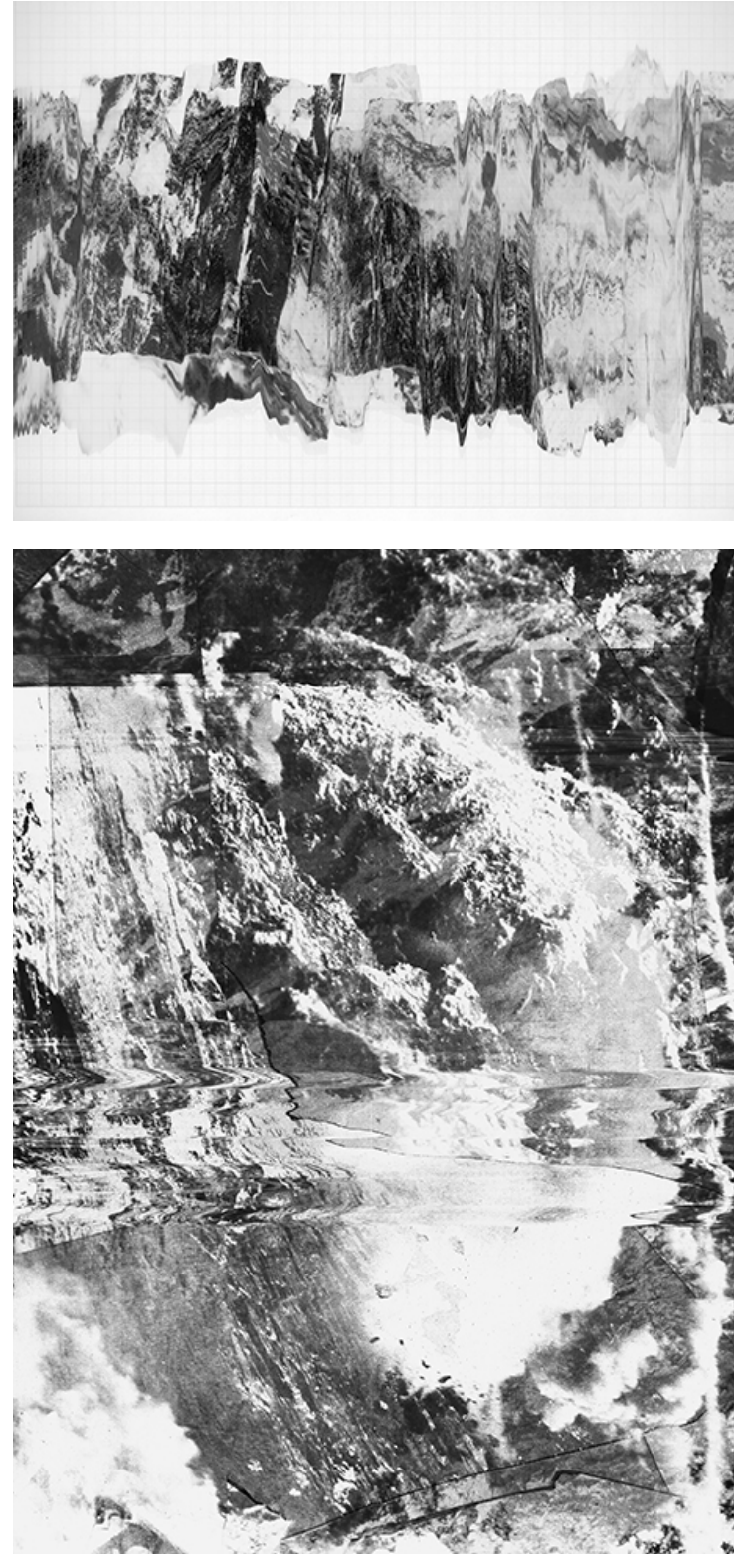
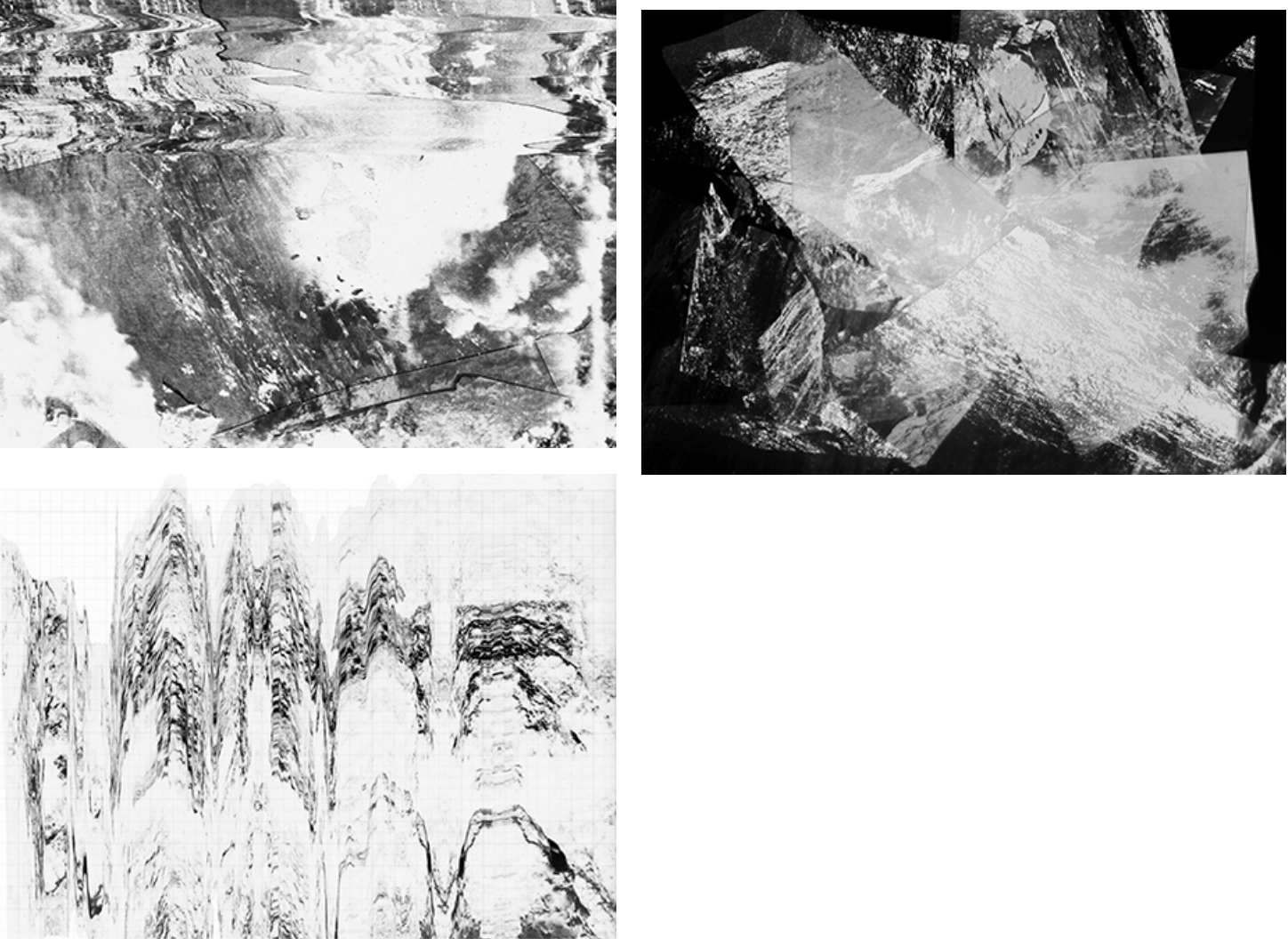


\section{Bibliografía}

Bahamonde, M., 1978. Diccionario de voces del Norte de Chile. Santiago de Chile: Editorial Nascimiento.

Benedetti, A., 2013. Los espacios fronterizos binacionales del sur sudamericano en perspectiva comparada. Revista Geo Pantanal, (15), pp. 37-62.

Blakemore, H., 1991. ¿Nacionalismo frustrado? Chile y el salitre, 1870-1895, en Dos Estudios sobre Sali- 67 tre y Política en Chile (1870-1895), Santiago, Dpto. de Historia USACH, pp.13-27.

Blaser, M., 2016. Is Another Cosmopolitics Possible, en Cultural Anthropology 31 (4): pp 545-570.

Buci-glucksmann, C., (2006). Estética de lo efímero. Madrid: Arena Libros.

Butler, J., 2002. Cuerpos que importan: sobre los límites materiales y discursivos del "sexo". Buenos Aires: Paidós.

Cereceda, P.; Osses, P.; Larraín, H.; Farías, M.; Lagos, M.; Pinto, R. y Schemenauer, R.S. Advective, orographic and radiation fog in the Tarapacá region, Chile. Atmospheric Research, 2002, nº 64, pp. 261-271.

Cereceda P.; Larraín, H.; Osses, P.; Farías, M. y Egaña, I. The climate of the coast and fog zone in the Atacama Desert of Tarapacá Region, Chile. Atmospheric Research, 2008a, no 87 , pp. 301-311.

Cereceda P.; Larraín, H.; Osses, P.; Farías, M. y Egaña, I. The spatial and temporal variability of fog and its relation to fog oases in the Atacama Desert, Chile. Atmospheric Research, 2008b, no 87, pp. 312-323.

Chakrabarty, D., 2000. Provincializing Europe: Postcolonial thought and historical difference. Princeton: Princeton University Press.

Clayton, S., 2003. Environmental Identity: A Conceptual and an Operational Definition. Identity and the natural environment: The psychological significance of nature. MIT Press. pp. 312-323.

Dalakoglou, D., y Harvey, P., 2012. Roads and Anthropology: Ethnographic Perspectivas on Space, Time and (Im)mobility”. Mobilities, vol. 7, n. 4: pp 459-465.

De la Cadena, M., 2010. Indigenous Cosmopolitics in the Andes: Conceptual Reflections Beyond Politics. Cultural Anthropology 25 (2): pp. 334-70. 
Déotte, J. L., 2013. La época de los aparatos. Buenos Aires: Adriana Hidalgo editora.

Descola, P. (2012). Más allá de la Naturaleza y Cultura. Buenos Aires: Amorrortu.

Despret, V., 2004. The Body We Care for: Figures of Anthropo-Zoo-Genesis.

Body \& Society 10 (2-3): pp. 111-34.

Dillon, Sarah., 2007. The Palimpsest: Literature, Criticism, Theory. London: Bloomsbury.

Escobar, A., 2014. Sentipensar con la Tierra. Nuevas Lecturas sobre Desarrollo, Territorio y Diferencia. Medellín: Ediciones UNAULA.

Escobar, M., y García, M. 2017. Camanchaca. Flujos etnonímícos y neblineros en la costa norte de Chile. Revista de geografía Norte Grande (68). pp. 11-32.

González, S., 2000. El proceso de chilenización de la región de Tarapacá: Ligas patrióticas y escuela fiscal, 1907-1950. En Travesía: Revista de Historia económica y social (3-4), pp. 55-68.

Grosfoguel, R., 2016. Del extractivismo económico al extractivismo epistémico y extractivismo ontológico: una forma destructiva de conocer, ser y estar en el mundo. Tábula Rasa, (24).

Haraway, D., 1997. Modest Witness@Second Millennium FemaleMan Meets OncoMouseTM: Feminism and Technoscience. Nueva York: Routledge.

Haraway, D., 2003. The Companion Species Manifesto: Dogs, People, and Significant Otherness. Chicago: Prickly Paradigm Press.

Heidegger, M., 1994. Conferencias y artículos. Barcelona: Ediciones del Serbal.

Ingold, T. 1993. The temporality of landscape. World Archaeology 25:152-74.

Ingold, T. 1997. The picture is not the terrain. Maps, paintings and the dwelt-in world. Archaeological Dialogues 4(1):29-31.

Larraín, H., 1978. Análisis demográfico de las comunidades de pescadores changos del Norte de Chile en el siglo XVI. New York: Tesis para optar al grado de Master of Arts in Department of Anthropology, State University of New York.

Larraín, H., 1979. Identidad cultural e indicadores eco-culturales del grupo étnico chango. Revista Norte Grande 1978-1979, N6, p. 63-76. 
Larraín, H., 1979. Cobija y el interior de Antofagasta en 1864, relato de un viaje. Actas del VII Congreso de Arqueología de Chile 1977 Vol. II. Santiago de Chile: Kultrún, 1979, pp. 429-441.

Latour, B., 2008. Reensamblar lo social. Una Introducción a la Teoría del Actor-Red. Buenos Aires: Ediciones Manantial.

Lippard, L., 1997. The Lure of the Local: Senses of Place in a Multi-Centered Society. New York: New Press.

Lizárraga, R., 1999. Descripción Breve de toda la tierra del Perú, Tucumán, Río de la Plata $y$ Chile. Buenos Aires: Academia Nacional de la Historia.

M'charek, Amade. 2014. "Race, Time and Folded Objects: The HeLa Error”. Theory, Culture \& Society 31 (6): pp. 29-56.

Mol, A., 1999. The Body Multiple: Ontology in Medical Practice. Durham, NC: Duke University Press.

Navarrete-Sitja, F. 2015. Aparatos para un territorio blando: relato de un viaje y reflexiones de un proceso de obra en Oasis de Niebla de Alto Patache, Región de Tarapacá, Chile.

Nicoletti, M., 2013. Araucanía-norpatagonia, la territorialidad en debate : perspectivas ambientales, culturales, sociales, políticas y económicas / María Andrea Nicoletti y Paula Gabriela Nuñez. - 1a ed. - San Carlos de Bariloche : IIDyPCa, 2013.

Nuñez, P., Conti, S., Barelli, A., y Bianchi, M. 2016. Fronteras conceptuales / Fronteras Patagónicas. Bariloche: Universidad Nacional de Río Negro. Editorial UNRN.

Pinto R., Larraín H., Cereceda P., Lázaro P., y Osses, P., 2001. Respuesta de la flora y fauna al influjo de las neblinas costeras (camanchacas), en períodos de "El Niño" (1997 - 1998) y “La Niña” (1998 - 2000) en la costa sur de Iquique, norte de Chile. 8o Encuentro de Geógrafos Latinoamericanos EGAL.

Romero-Toledo, H., 2019. "Extractivismo en Chile: la producción del territorio minero y las luchas del pueblo aimara en el Norte Grande”. Colombia Internacional (98): pp. 3-30.

Serres, M., y Bruno L. 1995. Conversations on Science, Culture and Time. Ann Arbor: University of Michigan Press.

Stengers, I., 2005. The Cosmopolitical Proposal. En Making Things Public, editado por Bruno Latour y Peter Weibel, 994-1003. Boston, MA: MIT Press.

Steyerl, H., 2014. Los condenados de la pantalla. Buenos Aires: Caja Negra Editorial. 
Weinberg, M. 2019. Especies compañeras después de la vida: pensando relaciones humano-perro desde la región surandina. Antípoda. Revista de Antropología y Arqueología (36): pp. 139-161.

Weischet, W. Las condiciones climáticas del desierto de Atacama como desierto extremo de la tierra. Revista Norte Grande, 1975, Vol. 1., N³ - 4, pp. 363-373.

Wittgenstein, L., 1988. Investigaciones filosóficas. Barcelona: Ed. Crítica.

Francisco Navarrete Sitja, licenciado en Artes, mención Plásticas y Magíster en Artes, mención en Artes Visuales de la Universidad de Chile (CL). Cursó el Programa de Estudios Independientes PEI del Museu d'Art Contemporani de Barcelona MACBA(ES). Actualmente, es Doctorando del Programa de Diseño y Comunicación de BAU Centro Universitario de Diseño de Barcelona y UVic-UCC. Trabaja como Co-director de L'Aquila Reale: Centro d’Arte e Natura di Civitella di Licenza(IT). Asimismo, es Integrante de la red internacional TSOEG Temporal School of Experimental Geography(UK), y colaborador de la red museal LicenzaMusei - Sistema Museale Urbano della Città di Licenza (IT). Situando sus prácticas estéticas desde la investigación artística y palimpsestos, se pregunta por la producción y configuración de los imaginarios paisajísticos.

Centro Universitario de Diseño de Barcelona y la Escuela de Doctorado UVic-UCC. Unidad de Doctorado BAU, línea de Investigación Diseño y sociedad. Políticas, arte y educación. www.francisconavarretesitja.com 